\title{
Do Open-Ended Questions Measure "Salient" Issues?
}

\author{
John G. Geer
}

In the early days of survey research, controversy swirled around whether pollsters should use closed-ended or open-ended questions (Lazarsfeld 1944). That debate has long been settled with closed-ended questions emerging as the overwhelming choice of survey researchers. A major reason for this decision was that fixed-format questions were easier to ask, code, and analyze than their free-format counterparts (Schuman and Presser 1981). Such pragmatic concerns are important, but the crucial issue should be whether open-ended questions provide important insights about public opinion. Yet the preference for closedended questions did not arise because of any systematic data that cast doubt on the ability of the open-ended questions to measure the attitudes of the public accurately. This article does not seek to resurrect the debate between the open and the closed form, since the latter is an integral part of our efforts to track public opinion. Instead, it hopes 
to provide a better idea of the capacity of open-ended questions to measure the attitudes of the public.

Proponents of open-ended questions, for instance, have long claimed that this format taps concerns that are important to respondents' political calculations (Campbell et al. 1960; Kelley 1983; Knight 1985; RePass 1971). RePass (1971, p. 391), for instance, argues that these kinds of questions permit citizens "to define [their] own issue space by naming issues that were salient to [them]." Kelley (1983) concurs, contending that the open-ended format allows researchers to tap the diverse attitudes of the American electorate. If these proponents are correct, it would call into question the infrequent use of the free-format question in surveys.

But not all scholars agree with these arguments, claiming instead that open-ended questions measure "superficial" concerns (Smith 1989, p. 84). Lodge, McGraw, and Stroh (1989, pp. 400-402) doubt that one set of open-ended questions asked by the National Election Studies (NES), the so-called like/dislike questions, accurately tap the electorate's salient attitudes about the candidates (see also Stroh, Lodge, and Callaghan 1990). Respondents, they argue, are unlikely to probe their memories in enough detail to remember correctly the pieces of information that generated their overall judgment of the candidates. Smith $(1989$, p. 84) expands on this point, writing that openended "comments do not reveal fundamental attitudes. Instead, the responses reveal more casual likes and dislikes, such as what the respondent has read in the papers recently or hears on television or in a conversation with a friend."

Thus, disagreement exists over the kinds of insights open-ended questions can yield about public opinion. But it is unclear whether critics or proponents are right, since there are few data that explicitly address their respective contentions. Using an experimental design, I test whether responses to open-ended questions tap the "salient" or "superficial" concerns of respondents. ${ }^{1}$ In an experiment, the presence of salient and superficial information can be manipulated, allowing one to determine whether open-ended questions reflect attitudes that are important to respondents. I relied on undergraduates as subjects, which, of course, limits the generalizability of these findings. But given the many threats to internal validity that might arise in distinguishing between salient and superficial comments, an initial experiment on students becomes an attractive way to test these rival claims.

1. Scholars have used the term "salient" to mean different things (see Schuman, Ludwig, and Krosnick 1986). Some view the term as indicating something in the immediate environment that may or may not be important. Others equate the term with importance. In this article, the latter meaning is used. 


\section{The Experiment}

This experiment was based on 106 students from a class in statistics in the fall of 1989 at Arizona State University. The first task in running the experiment was to distinguish between important and superficial (or "nonsalient") information. Rather than arbitrarily deciding what information was salient, I conducted a pre-test on September 19 (2 weeks prior to the experiment) that asked these students to rate the importance of 21 issues, ranging from construction of new prisons to abortion. (The questions were part of a wide-ranging survey that sought to avoid sensitizing subjects to the subsequent experiment.) Specifically, I inquired whether students viewed the issue as "not at all important, not very important, somewhat important, very important, or haven't you thought much about it." As one might guess, issues such as welfare spending, taxes, education, drugs were all viewed as important by the students. In each case, over 50 percent of the students rated these issues as "very important." In contrast, only about 10 percent of the students considered issues like construction of prisons, price supports for dairy farmers, and foreign aid "very important."

Using this information as a basis, I constructed two articles for students to read about George Bush (see Appendix). I chose to focus on Bush, since nearly all students were likely to have some preexisting opinions about him. The information in the experiment, therefore, would be only one part of their general knowledge about the president, allowing one to estimate the possible effects of the articles in the face of those preexisting attitudes.

The first article stated that Bush had increased spending for drug enforcement, proposed lowering federal taxes, cut spending for education, lowered spending for social-welfare programs, and increased the size of the defense budget. These issues were considered salient. The second article highlighted nonsalient issues; namely, that Bush had increased government spending for farmers, lowered aid to the Third World, cut spending for the construction of new prisons, trimmed the FBI's budget, and increased spending for the United Nations. These articles, as the Appendix shows, were identical in form except for the five issues embedded in the second paragraph of each story. ${ }^{2}$

For purposes of control, I drafted one additional article, which had nothing to do with George Bush. Instead, it talked about some activi-

2. In an effort to strengthen the external validity of the study, students were told that Bush was a likely presidential candidate in 1992 and in anticipation of that event one of the wire services wrote a story about Bush's accomplishments in his first 9 months in office. The purpose of this article was, therefore, to prepare citizens for the upcoming presidential campaign. 
ties at the university. Given the hypothesis that open-ended comments may reflect superficial items, we need to know what comments would look like without exposure to any information about Bush. For example, mentions about the economy might be high regardless of whether one reads about Bush's view on the matter or not. This article provides that comparison.

I randomly distributed the three articles to the students. ${ }^{3}$ To prevent subjects from knowing the articles were different, there was a cover sheet asking them not to open the survey. Once all surveys were distributed, students turned the page and read the article. After reading it, they ripped the article from the packet and passed it in. This exercise served as a minor distractor for the students. It also lessened the chance they might notice that other students were reading different material. Finally, by handing in the article, students could not refer to that material when answering the open-ended questions in the latter part of the survey.

As an additional distractor, students answered six closed-ended questions about state politics. These questions dealt with attitudes toward the governor, the ex-governor, the upcoming gubernatorial election, and some local issues. These six questions had the additional benefit of decreasing the chances the students would guess the objective of the experiment; thus, reducing "demand characteristics" (Orne 1962).

In the next part of the survey, I asked students to answer the NES's open-ended questions about George Bush, ${ }^{4}$ encouraging them to write as many comments as they wanted. As the final part of the survey, students answered a set of questions that tested whether they could recall accurately the information contained in the article they had just read about 20 minutes ago. Some of the nonsalient information may not have been stored in memory by students, making it impossible for them to use it when answering the open-ended questions about Bush. By asking students to recall Bush's position on each of the five issues in the article, one could test for that possibility. Those students who read about the activities at the university also answered five recall questions so as to make each survey comparable.

Once the participants completed the surveys, I developed a coding scheme for the responses to the open-ended questions about Bush.

3. I conducted an analysis of variance on political interest, age, sex, race, and partisanship of the three groups and no statistically significant differences emerged for these variables, bolstering one's confidence that the randomization was effective.

4. The wording of the questions is as follows: Is there anything in particular about George Bush that might make you want to vote for him? Is there anything in particular about George Bush that might make you want to vote against him? 
First, I created categories that dealt with the 10 issues that had been mentioned in the two articles about the president. Any mention that dealt broadly with one of the 10 topics I treated as one of those issues. ${ }^{5}$ Thus, students were not required to repeat exactly what appeared in the articles. Those comments that did not address the 10 issues mentioned in the article were coded into separate categories.

\section{Results}

Table 1 reports the mean number of responses per student in each of the three groups for the 10 issues discussed in the two articles about George Bush. ${ }^{6}$ In the first part of the table, it is clear that the responses of students exposed to salient issues were affected. For instance, the mean number of comments per respondent concerning defense policy was .57 for those who had read about Bush's proposal concerning the military's budget. In contrast, those students exposed to information about the university mentioned defense spending just .11 times per respondent. The same pattern holds for each of the five issues: the group exposed to the salient information made more comments about the topic than the other two groups. Only in the case of economic concerns were the differences not large enough to be statistically significant $(p<.05) .^{7}$

The second part of table 1 clearly shows, however, that those people exposed to the nonsalient information made almost no comments about any of the five issues. Not a single student, for instance, mentioned

5. As a very rough indication of coding reliability, I randomly coded 10 interviews on a separate sheet of paper, noting only the last four digits of the students' social security number. One week later I content analyzed the entire set of responses, comparing the coding for same 10 interviews. Of the 33 open-ended comments, only two comments were coded differently, and they involved issues outside of the 10 mentioned in the two articles. Given the strength of these results, I did not undertake a more systematic check.

6. I examined the differences between the three groups for issues not listed in table 1 , such as the environment, the "flag," and concerns about personal characteristics. No statistically significant differences arose in any of the issues I examined.

7. Table 1 only presents the $F$-test to determine if differences between the three groups are statistically significant. One could, however, argue that by comparing all three groups at once, some important differences between any two of the groups could be obscured. To test for this possibility, I ran statistical tests comparing the responses of the "salient" information group to the "nonsalient" information group and the "salient" information group to the group receiving no political information. These tests turned up only two statistical differences from that in table 1. First, mentions about Bush's drug policy did not reach statistical significance ( $p=.66$ ) when comparing the "salient" information group to the "other" information group. Second, the total number of comments made by the "salient" information group were larger than that of the "nonsalient" information group at $p=.05$. 


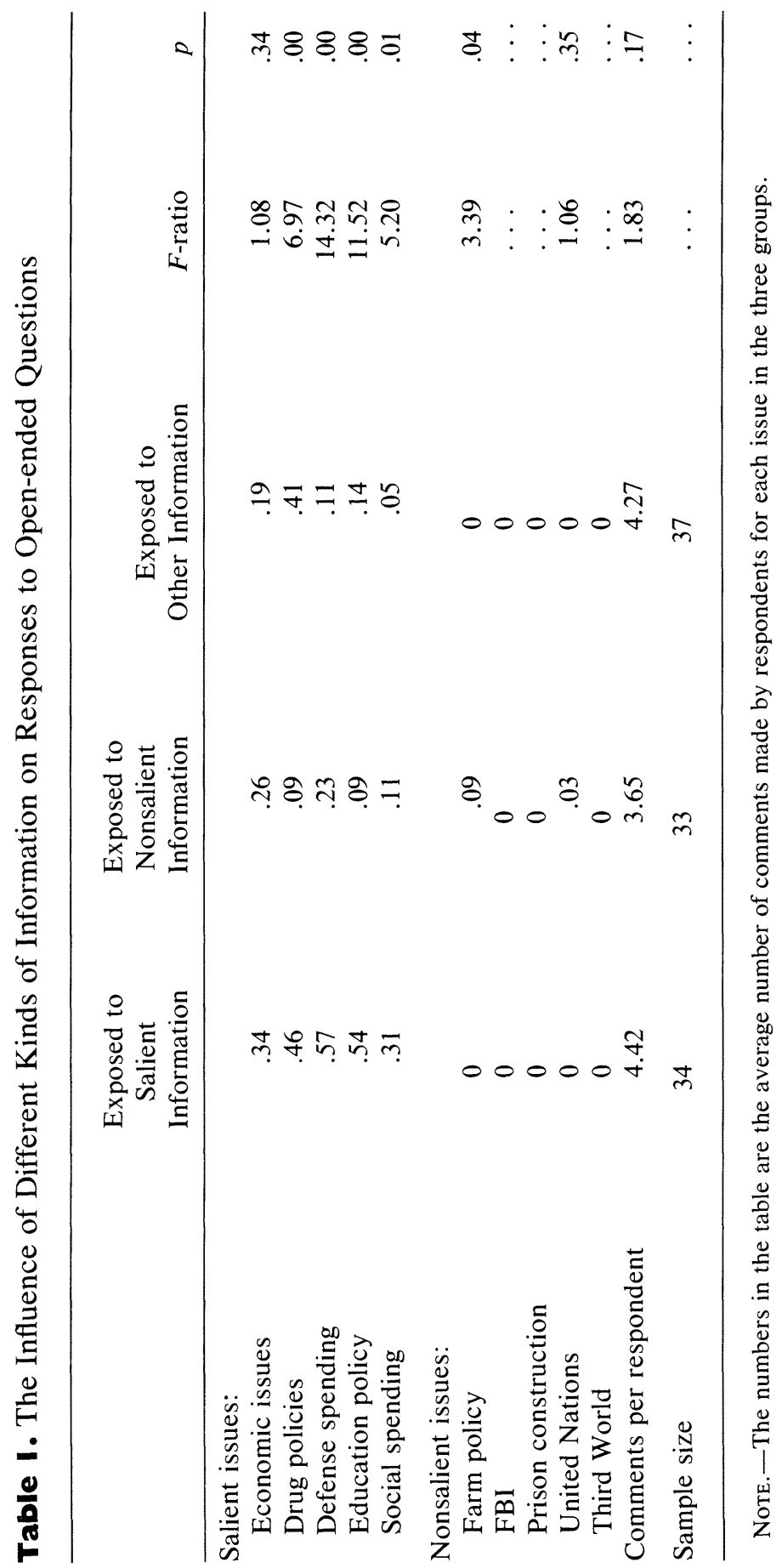


the FBI's budget, construction of new prisons, or policy toward the Third World. Even worries about crime, which could have been activated by discussions of the FBI or prisons, were absent from the comments of the subjects exposed to the nonsalient information. Two small exceptions to this pattern arise, however. One student did refer to George Bush's policy on funding the United Nations, suggesting that the article may have had some influence on his attitudes. In this case, however, the differences between the three groups were not statistically significant. Three other students did mention farm policy in response to the "like/dislike" questions, and these differences met the standard levels of statistical confidence. But this result is hardly evidence consistent with the claim that open-ended questions measure superficial attitudes. ${ }^{8}$

A rival hypothesis, however, is that the students may not have remembered the information contained in the nonsalient article, which could have produced these results. That hypothesis goes unsupported, since 70 percent of the students recalled correctly Bush's position on all five nonsalient issues mentioned in the article. For the students who read the salient article, about 80 percent of these participants correctly recalled Bush's views on all five issues. This 10 percentage point gap was not statistically significant ( $p=.37$ ). It is, of course, unclear how much searching of memory these students undertook in answering the open-ended questions, but the results cast doubt on claims by some scholars that citizens may not be "willing and able to conduct a search for relevant information in memory" when answering such questions (Lodge, McGraw, and Stroh 1989, p. 400).

\section{Conclusion}

How should one interpret these results? To begin, the fact that the nonsalient information had little effect on the responses to the openended questions undercuts the argument that citizens answer these questions simply with information they recently learned. This particular finding, therefore, suggests that scholars have overstated the claim that open-ended questions tap superficial concerns.

One could, however, stress the alternative finding that the substantive content of the responses did change when subjects were exposed

8. An interesting story arose upon closer examination of the three students who mentioned farm policy. One of the students who referred to Bush's position on spending for farmers stated in the pre-test that agricultural policy was central to her when choosing a candidate for the presidency. Thus, the open-ended comment about farming may reflect an important concern for her. 
to salient information. Although one might view this result as a problem for open-ended questions, it need not be one. First, it appears that responses to all types of questions, whether open-ended or closedended, are susceptible to recent information. Zaller and Feldman (1990) have marshalled good evidence showing that closed-ended questions are also vulnerable on this front. Second, the findings presented in the first part of table 1 may actually be an asset for open-ended questions. Since people's attitudes are not static, there is reason to expect some change in them. Thus, if citizens hear that Bush plans to raise taxes, that information is likely to alter many individuals' views of him. Consequently, when critics complain that responses to openended questions may reflect information respondents "have seen on recent television or read in the newspapers" (Smith 1989), they are assuming that "recent" information cannot be important to people's attitudes. Such an assumption seems unreasonable. The purpose of campaigns, for instance, is to saturate voters with propaganda in the hope they will support their candidate on election day. The data presented here show quite strongly that these students did not react to every piece of information that they read. Rather they responded to only part of it, and those parts were issues that had been deemed by them as a collectivity to be important.

The final implication of this article concerns the concept of "priming." Iyengar and Kinder (1987, p. 63) demonstrate that "by calling attention to some matters while ignoring others, television news influences the standards by which governments, presidents, policies and candidates for public office are judged." The results presented here indicate that newspapers can also prime attitudes, which bolsters their argument. Interestingly, these results also suggest that the impact of priming may depend on the inherent importance of the issue being discussed by the news media. That is, the news media probably can prime attitudes about the economy more readily than attitudes about the construction of new prisons.

These results, of course, are only a first step toward developing a sounder empirical base for assessing the ability of open-ended questions to measure public opinion. The evidence presented here is narrow in focus, indicating that much more work needs to be done. But the results question the claims of critics that open-ended questions tap just superficial concerns, suggesting these questions can be useful in our efforts to assess public opinion. These questions are not without their flaws, but given the quest of survey researchers to estimate the views of citizens as accurately as possible, perhaps pollsters should be more willing to include open-ended questions in future surveys of public opinion. 


\section{Appendix}

\section{Article 1: Salient Information}

The 1992 presidential election is just three years away. All indications are that George Bush will run for another term. It has been over 20 years since a sitting president has not sought a second term. Bush is unlikely to break that streak. In an effort to inform the public of Bush's plans and accomplishments over the last nine months, one of the wire services decided to run a brief article summarizing some of Bush's activities. The paragraphs below are a copy of that article, which appeared on October 16, 1989.

\section{WHAT HAS GEORGE BUSH DONE?}

George Bush has been in office a little over 9 months, but all ready visions of the 1992 Presidential Election are dancing in his head. Even though the election is three years away, candidates for the presidency must already begin to organize their campaign. While potential contenders plot their strategies, we have decided to help the potential voters of 1992 by reviewing some of Bush's proposals and actions over the last nine months. Not every action will be covered here, but we have chosen to mention things that might have gone unnoticed by the public.

First, Bush has increased Government spending for drug enforcement by 10 percent since taking office. During this same time, Bush has sought to lower the amount of Government income taxes by 6 percent over the next two years. A third action by Bush is that he has lessened Government spending for education by 9 percent over the next three years. Fourth, Bush has tried to lower Government spending for social-welfare programs by 8 percent for next year's budget. Finally, Bush plans to increase Government spending for defense by 5 percent for the 1991-92 budget.

Bush will, of course, continue to adopt and propose policies over the next three years. And at regular intervals, we shall try to bring these matters to the attention of our readers. In this way, citizens too can organize as the next presidential election approaches.

\section{Article 2: Nonsalient Information}

The 1992 presidential election is just three years away. All indications are that George Bush will run for another term. It has been over 20 years since a sitting president has not sought a second term. Bush is unlikely to break that streak. In an effort to inform the public of Bush's plans and accomplishments over the last nine months, one of the wire services decided to run a brief article summarizing some of Bush's activities. The paragraphs below are a copy of that article, which appeared on October 16, 1989. 
George Bush has been in office a little over 9 months, but all ready visions of the 1992 Presidential Elections are dancing in his head. Even though the election is three years away, candidates for the presidency must already begin to organize their campaign. While potential contenders plot their strategies, we have decided to help the potential voters of 1992 by reviewing some of Bush's proposals and actions over the last nine months. Not every action will be covered here, but we have chosen to mention things that might have gone unnoticed by the public.

First, Bush has increased Government spending for farmers by 10 percent since taking office. During this same time, Bush has sought to lower the amount of Government subsidies for Third World nations by 6 percent over the next two years. A third action by Bush is that he has lessened Government spending for construction of new prisons by 9 percent over the next three years. Fourth, Bush has sought to lower Government spending for the FBI by 8 percent for next year's budget. Finally, Bush plans to increase Government spending for the United Nations by 5 percent for the 1991-92 budget.

Bush will, of course, continue to adopt and propose policies over the next three years. And at regular intervals, we shall try to bring these matters to the attention of our readers. In this way, citizens too can organize as the next presidential election approaches.

\section{Article 3: Other Information Group}

As undergraduates at ASU, you have certain opinions about how the university is run. Below is an article about ASU released by the upper administration of the University. I would like you to read the article, thinking about its accuracy.

\section{SOME REFLECTIONS ON ASU}

Arizona State University is one of the fastest growing schools in the nation. At present there are over 40,000 students. By the year 2000, some experts think enrollment will swell to 60,000 . Given this growth, the administration wants to emphasize certain things about the University. First, the administration cares about the quality of life at ASU and will continue to adopt policies directed toward that goal. Second, the administration contends that the undergraduate student body at ASU helps make the time here a good experience, and therefore more effort must be expended in attracting a talented and diverse set of undergraduates. Third, ASU is a tough school to do well in and thus does not deserve the reputation as a "party" school. Fourth, the faculty are generally good scholars who try to teach quality courses. Fifth, the size of the classes needs to be a lot smaller so there can be more interaction with the faculty, requiring additional resources to lessen the number of students in each class. 
Thus, as long as ASU receives the funding necessary to support its growth, there is good reason to believe that ASU's reputation will grow as fast as its enrollment.

\section{References}

Campbell, Angus, Philip Converse, Warren Miller, and Donald Stokes. 1960. The American Voter. New York: Wiley.

Iyengar, Shanto, and Donald Kinder. 1987. News That Matters. Chicago: University of Chicago Press.

Kelley, Stanley. 1983. Interpreting Elections. Princeton, NJ: Princeton University Press.

Knight, Kathleen. 1985. "Ideology in the 1980 Election: Ideological Sophistication Does Matter." Journal of Politics 47:828-53.

Lazarsfeld, Paul F. 1944. "The Controversy over Detailed Interviews-an Offer for Negotiation." Public Opinion Quarterly 8:38-60.

Lodge, Milton, Kathleen M. McGraw, and Patrick Stroh. 1989. "An Impression-driven Model of Candidate Evaluation." American Political Science Review 83:399-420.

$\rightarrow$ Orne, M. T. 1962. "On the Social Psychology of the Psychological Experiment: With Particular Reference to Demand Characteristics and Their Implications." American Psychologist 17:776-83.

RePass, David E. 1971. "Issue Salience and Party Choice." American Political Science Review 65:389-400.

Schuman, Howard, Jacob Ludwig, and Jon A. Krosnick. 1986. "The Perceived Threat of Nuclear War, Salience, and Open Questions." Public Opinion Quarterly 50:519-36.

Schuman, Howard, and Stanley Presser. 1981. Questions and Answers in Attitude Surveys. New York: Academic Press.

Smith, Eric R. A. N. 1989. The Unchanging American Voter. Berkeley: University of California Press.

Stroh, Patrick K., Milton Lodge, and Karen Callaghan. 1990. "Impression-driven and Memory-based Explanations of Political Candidate Evaluation." Paper presented at the annual meeting of the Midwest Political Science Association, Chicago.

Zaller, John, and Stanley Feldman. 1990. "Answering-Questions vs. Revealing Preferences: A Simple Theory of the Survey Response." Paper presented at the fifth annual meeting of the Political Methodology Society. 